\title{
The challenges of estimating biological age
}

\section{A comparison of nine different approaches over a period of 20 years reveals the most promising indicators for biological age.}

\section{ALEXEY MOSKALEV}

Related research article $\mathrm{Li} X$, Ploner $\mathrm{A}$, Wang Y, Magnusson PKE, Reynolds C, Finkel D, Pedersen NL, Jylhävä J, Hägg S. 2020. Longitudinal trajectories, correlations and mortality associations of nine biological ages across 20-years follow-up. elife 9: e51507. DOI: 10.7554/eLife.51507

$\mathrm{T}$ o see if treatments to ward off aging work, first we need a way to measure biological age reliably (Moskalev, 2019). Biological age is a complex parameter involving the calendar age of a person, their health as relating to their age, and medical signs of when they might die of old age. Historically, the first estimates of biological age were based on markers that could be measured in the clinic (such as inflammation, glucose resistance, and endocrine markers) and on functional tests (such as cognitive function and cardiorespiratory fitness; reviewed in Jia et al., 2017). Such markers have a direct clinical interpretation, but even if they predict mortality better than passport age, it is unclear to what extent they measure biological aging itself, rather than health deterioration for other reasons. Additionally, these markers often only work well as averaged indicators in very large samples, and vary a lot between individuals. However, it may be possible to overcome these limitations by using artificial intelligence to generate models using several aging biomarkers (Zhavoronkov et al., 2019).
Other approaches, based on a deeper understanding of the molecular and cellular causes of aging, include measuring the levels of p16 (a marker for cellular senescence or when a cell stops dividing) and measuring the telomere length in leukocytes (biological age increases as telomere length decreases; Waaijer et alı, 2012; Epel et al., 2009). Theoretically, these markers should be more sensitive to early signs of aging (as opposed to mortality and frailty) but, similar to clinical markers for individual patients, they lack robustness and reproducibility. This is because aging is a multi-level process, so markers of individual mechanisms cannot cover all its aspects.

A third approach is to use 'omics' (that is, to analyze the transcriptome, methylome, proteome and metabolome). Changes in the 'omes' are the result of changes in the organism at different levels, making them a useful way to approach the complexity of the aging process. Using this approach, there is no single biological age, but rather a metabolic, proteomic or methylome age. Multi-omics approaches have also been used to assess the rate of aging (Solovev et alo, 2020).

Within omics, analyses of DNA methylation or epigenetic clocks are the most robust indicator of age-related changes and have become a booming area of research (Bell et al., 2019). But questions still remain. To what extent are epigenetic clocks a function of age, and to what extent part of biological aging? How does the epigenome change with age? How closely are epigenetic clocks associated with mortality? Is it possible to reverse the epigenetic age, for 
example through lifestyle changes or interventions? Diet, exercise, education and lifestyle factors seem to be able to influence the rate of aging according to the epigenetic clock (Quach et al., 2017; Gensous et al., 2019; SaeLee et al., 2018). Certain drugs can slow down the epigenetic clock in cells cultured in the lab (Horvath et al., 2019) and certain treatments have also proved to be effective in vivo (Chen et al., 2019; Fahy et al., 2019).

Now, in eLife, Sara Hägg from the Karolinska Institute and colleagues from the University of California Riverside, Indiana University Southeast and Jönköping University - with Xia $\mathrm{Li}$ as first author - study how nine different methods to estimate biological age change over time in a cohort of 845 middle-aged and older individuals from Sweden who were studied over a period of 20 years (Li et al., 2020). Three of the biological ages measured were functional (cognitive function, functional aging index, and frailty index) and four were based on the levels of DNA methylation (called Horvath, Hannum, PhenoAge and GrimAge). The other two were telomere length (measured by qPCR) and physiological age (calculated as a composite score of clinical measurements such as body-mass index or waist circumference, and blood biomarkers such as hemoglobin or cholesterol).

This study is unique because it compares several approaches at once and evaluates how the measurements change over time: functional data and biological samples were collected nine times between 1986 and 2014. The profiles for the three functional measurements indicated that accelerated aging started around the age of 70, whereas the other biological ages showed linear growth with time.

The authors found sex differences in the mean levels of the different biological ages. Women exhibited longer telomere length and lower DNA methylation age compared to men, but also averaged higher in two of the three functional estimates. Telomere length showed the weakest correlations with both chronological age and with the other measurements. The highest correlations were between two of the DNA methylation ages (Horvath and Hannum), and between the functional aging index and the other two functional biological ages. Regarding the ability of biological ages to predict agerelated mortality, one of the functional estimates (frailty index) and one of the methylation clocks (GrimAge) were the best predictors, while telomere length was the worst.
These results indicate that methylation age and frailty index are the most promising approaches to estimating biological age, and underline the value of assessing these estimates overtime in the same population.

Alexey Moskalev is in the Institute of Biology, Komi Science Center, Ural Branch of the Russian Academy of Sciences, and Syktyvkar State University, both in Syktyvkar, Russia, and the Engelhard Institute for Molecular Biology, Russian Academy of Sciences, Moscow, Russia amoskalev@list.ru

(D) https://orcid.org/0000-0002-3248-1633

Competing interests: The author declares that no competing interests exist.

Published 11 February 2020

\section{References}

Bell CG, Lowe R, Adams PD, Baccarelli AA, Beck S, Bell JT, Christensen BC, Gladyshev VN, Heijmans BT, Horvath S, Ideker T, Issa J-PJ, Kelsey KT, Marioni RE, Reik W, Relton CL, Schalkwyk LC, Teschendorff AE, Wagner W, Zhang K, et al. 2019. DNA methylation aging clocks: challenges and recommendations. Genome Biology 20:249. DOI: https://doi.org/10. 1186/s13059-019-1824-y

Chen L, Dong Y, Bhagatwala J, Raed A, Huang Y, Zhu H. 2019. Effects of vitamin D3 supplementation on epigenetic aging in overweight and obese African Americans with suboptimal vitamin D status: a randomized clinical trial. The Journals of Gerontology: Series A 74:91-98. DOI: https://doi.org/10.1093/ gerona/gly223

Epel ES, Merkin SS, Cawthon R, Blackburn EH, Adler NE, Pletcher MJ, Seeman TE. 2009. The rate of leukocyte telomere shortening predicts mortality from cardiovascular disease in elderly men: a novel demonstration. Aging 1:81-88. DOI: https://doi.org/ 10.18632/aging. 100007

Fahy GM, Brooke RT, Watson JP, Good Z, Vasanawala SS, Maecker H, Leipold MD, Lin DTS, Kobor MS, Horvath S. 2019. Reversal of epigenetic aging and immunosenescent trends in humans. Aging Cell 18: e13028. DOI: https://doi.org/10.1111/acel.13028, PMID: 31496122

Gensous N, Franceschi C, Santoro A, Milazzo M, Garagnani P, Bacalini MG. 2019. The impact of caloric restriction on the epigenetic signatures of aging. International Journal of Molecular Sciences 20:2022. DOI: https://doi.org/10.3390/ijms20082022

Horvath S, Lu AT, Cohen H, Raj K. 2019. Rapamycin retards epigenetic ageing of keratinocytes independently of its effects on replicative senescence, proliferation and differentiation. Aging 11:3238-3249. DOI: https://doi.org/10.18632/aging.101976

Jia L, Zhang W, Chen X. 2017. Common methods of biological age estimation. Clinical Interventions in Aging 12:759-772. DOI: https://doi.org/10.2147/CIA. S134921, PMID: 28546743

Li X, Ploner A, Wang Y, Magnusson PKE, Reynolds C, Finkel D, Pedersen NL, Jylhävä J, Hägg S. 2020. 
Longitudinal trajectories, correlations and mortality associations of nine biological ages across 20 -years follow-up. eLife 9:e51507. DOI: https://doi.org/10. 7554/eLife. 51507

Moskalev A. 2019. Introduction. In: Moskalev A (Ed). Biomarkers of Human Aging. Cham: Springer International Publishing. p. 1-4. DOI: https://doi.org/ 10.1007/978-3-030-24970-0_1

Quach A, Levine ME, Tanaka T, Lu AT, Chen BH, Ferrucci L, Ritz B, Bandinelli S, Neuhouser ML, Beasley JM, Snetselaar L, Wallace RB, Tsao PS, Absher D, Assimes TL, Stewart JD, Li Y, Hou L, Baccarelli AA, Whitsel EA, et al. 2017. Epigenetic clock analysis of diet, exercise, education, and lifestyle factors. Aging 9 419-446. DOI: https://doi.org/10.18632/aging.101168, PMID: 28198702

Sae-Lee C, Corsi S, Barrow TM, Kuhnle GGC, Bollati V Mathers JC, Byun HM. 2018. Dietary intervention modifies DNA methylation age assessed by the epigenetic clock. Molecular Nutrition \& Food Research 62:e1800092. DOI: https://doi.org/10.1002/mnfr. 201800092, PMID: 30350398
Solovev I, Shaposhnikov M, Moskalev A. 2020. Multiomics approaches to human biological age estimation. Mechanisms of Ageing and Development 185:111192. DOI: https://doi.org/10.1016/j.mad.2019.111192, PMID: 31786174

Waaijer ME, Parish WE, Strongitharm BH, van Heemst D, Slagboom PE, de Craen AJ, Sedivy JM, Westendorp RG, Gunn DA, Maier AB. 2012. The number of p16INK4a positive cells in human skin reflects biological age. Aging Cell 11:722-725. DOI: https://doi.org/10.1111/j.1474-9726.2012.00837. x, PMID: 22612594

Zhavoronkov A, Mamoshina P, Vanhaelen Q,

Scheibye-Knudsen M, Moskalev A, Aliper A. 2019. Artificial intelligence for aging and longevity research: recent advances and perspectives. Ageing Research Reviews 49:49-66. DOI: https://doi.org/10.1016/j.arr. 2018.11.003, PMID: 30472217 